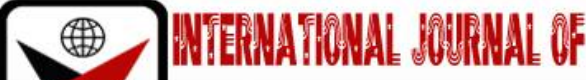

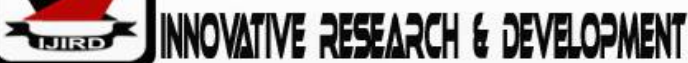

ISSN 2278 - 0211 (Online)

\section{Slavery and Trauma in Andre Brink's Philida}

\author{
Bello Usman \\ Senior Lecturer, Department of General Studies, Federal Polytechnic, Damaturu, Nigeria
}

\begin{abstract}
:
The present paper aims to examine the deep psychological and physical trauma that victims of slavery live with. The inhuman degradation that slaves are made to undergo underlines the aberration of this institutionalized evil. The essay will also highlight the sort of trauma that slave owners also live with. Andre Brink in the novel Philida was attempting to show the historical antecedents of South African slavery especially, in the Cape. He used his family historical documents to offer a close study of the trauma that slavery has caused millions over the centuries - from the mid seventeenth century to 1834 when slavery was abolished in South Africa. This makes the present study significant because it has delved into the physical and psychological cost of that evil. Philida is a recently published novel and eminent researchers have just started working on it. This work will analyze the novel using Trauma theory in order to underscore the debilitating effect that slavery has had on people in South Africa for more than three hundred years. Slavery has affected not only slaves but also their masters. The implication is that the feeling of trauma is felt both ways. Slavery has also put a lie to the feeling of white blood purity in South Africa. Philida had shown how slave masters sleep with their black slaves and thus have children through them. Cornelis Brink's mother Petronella, a former slave, was black. Philida's father was a white man. Philida's child Willempie has blue eyes.
\end{abstract}

Keywords: Baas, caab, ouma nella, philida, slavery, trauma

\section{Introduction}

Andre Brink's Philida is an important historical novel that highlighted the evils inherent in the institution of slavery. The novel, through the use of a narrative technique that delves into the inner psyche of slaves such as the protagonist of the story Philida, is able to underline the traumatic experiences that slavery has placed millions over the centuries that this evil practice was in place. Brink was also able to underline the blood relationship between slave owners and their slaves. In a way, he is pointing out that the master - slave relationship has a much deeper significance than even those who perpetuated it would be willing to accept. Andre Brink is virtually, presenting his family's history in South Africa. The intention of the essay is to highlight the trauma that Philida, the novel's protagonist had passed through both at the hands of Francois 'Frans' Brink and his father Cornelis Brink. It is also important to stress the fact that even though slave masters across the centuries sleep and have children with their slaves; yet, they do not perceive slaves as human. They see them as sub-human. In Philida the shoe symbolism is quite fundamental in showing the core philosophy underpinning the institution of slavery and thus, the author made it quite obvious:

The shoes on my feet. What he says about the shoes he promised me from the very first day. Because he knew, as I knew, as the whole world know: the man or the woman with shoes on their feet, they cannot be slaves, they are free, shoes mean that they are not chickens or donkeys or pigs or dogs, they are people. (Philida 15)

Part of the trauma that slaves had to pass through is both psychological and physical. The act of wearing shoes has been entrenched in the practice of slavery in order to further demean the basic humanity of the slaves. They are viewed in the same rank as other household animals and so they had to move around like them. Francois Brink knew this will touch a nerve deep within Philida and would lead her to acquiesce to his sexual advances. Although, Frans and Philida both love each other in their different ways; the reader can clearly see that Philida has been violated, used and dehumanized. In any case, Philida cannot say no to the son of her owner since slaves do not have a say in what happens to them. Petronella 'Ouma Nella', like Philida was also sexually brutalized by the grandfather of Frans. When Cornelis Brink wanted to rape Philida in the bamboo copse she reminded him of what his father did to Petronella: 'Frans lie with me, she repeats. I am his woman now. It's a bad thing the Ouman want to do in this bamboo place today...My Ouma Nella tell me long ago what your father does to her, she says.' (Philida 84). Petronella was also suffering from the deep trauma as a result of the sexual abuse she suffered from Pa Johannes which eventually, produced Cornelis Brink and his siblings. The novel did not however, stop at chronicling the abuse of slaves and their subsequent trauma; Andre Brink recounts the trauma that slave owners' experiences. Cornelis Brink was suffering from 'adult catastrophic psychic trauma' (Krystal 80). The collapse of his wine business and the process of his aging - are a cause for trauma in his life. 


\section{Literature Review}

\subsection{Trauma in Philida}

The pain associated with the experience of slavery can lead to both physical and psychological problems for slaves. Slavery can also affect slave masters in other devastating ways. In Philida the lives of Philida, Petronella, Cornelis Brink, and a host of other characters attests to the presence of trauma. Cathy Caruth offers an exhaustive definition of trauma:

In its most general definition, trauma describes an overwhelming experience of sudden or catastrophic events in which the response to the event occurs in the often delayed, uncontrolled repetitive appearance of hallucinations and other intrusive phenomena. (Caruth 11).

This definition clearly underlines the experiences of the key characters in Andre Brink's narrative. The constant sexual harassment of the protagonist, Philida, the unfulfilled promises by Frans and the debilitating conditions of living as a slave all combine to make life very difficult - both physically and psychologically for her. It is also noteworthy to emphasize the presence of constant thoughts and memories of past acts of dehumanization that Philida had undergone. These thoughts are a constant torment and they refresh the pains all over again. Philida is a historical novel in which the evil of slavery was properly situated in the South African context. Slavery and the slave trade started in the midseventeenth century. It started with very few slaves to many thousands by the 1820s and 1830s in the Cape. Trauma and traumatic experiences in slavery within the Cape is therefore, an historical issue. Enslaved peoples have been victims of traumatic experiences for more than three hundred years. By the time slavery was outlawed and slaves were emancipated in 1834, the deep physical and psychological scars will continue to fester for many generations. The trauma in slavery and after slavery has thus become a reality for victims:

...trauma seems to be much more than a pathology, or the simple illness of a wounded psyche: it is always the story of a wound that cries out, that addresses us in the attempt to tell us of a reality or truth that is not otherwise available. (Caruth 4)

Andre Brink is presenting to readers a deep-seated wound that has been inflicted on human beings through an institutionalized system of evil. He delved into the history of his slave and landowning family in order to expose the systematic human aberration that was committed. He also called to question the purity of white racial blood that the minority whites in South Africa lay claim to, in the light of the common practice prevalent during the era of slavery when slave masters had sexual relations with their female slaves.

Another form of trauma in Philida is the 'Adult Catastrophic Psychic Trauma.' This type of trauma is prevalent in people who are quite advanced in their age: '...the adult catastrophic trauma state is determined by the presence of unavoidable danger.' (Krystal 80). This type of trauma was noticeable in Cornelis Brink when he realizes his wine business is sinking and his farm is fast deteriorating. He was inevitably, in debt and running bankrupt. He was also facing the midlife crisis of increasingly reduced sexual libido. These are the types of intractable issues that Cornelis cannot resolve so they become a deep and recurring psychological problem. Andre Brink's thesis in Philida is to present past events and memory in the way they mix in order to explain clearly relationships that subsists in the past to the present. Whitehead (2004) asserted that memory and trauma are related: 'The rise of trauma fiction in recent decades is inseparable from the turn to memory in literary and historical studies.' (Whitehead 81). Within Philida memory has been used as a vehicle through which the characters present to the reader traumatic events and feelings. We read of recurring thoughts of intense acts of brutality against these characters which are repeatedly replayed and enacted, in some instances in other forms by these victims. Literary artists such as Brink also use the medium of history and the memory of key events it evokes to critically assess interconnections and how people are affected by them. Fundamental events of history like the slave trade and the institution of slavery are per force vital themes that excites literary artists to look closely into the basic psyche of all the characters involved in that warped human drama.

\subsection{The Use of Trauma Theory in Non-European Texts}

Philida is a novel written by an African writer. The setting and the nuances within the text all reflects the geography of the continent. The Europeans within the text are colonialists - both British and Dutch (Afrikaners). It is quite imperative to note that in the context of periodization, that the narrative is presenting a scenario in which the European conqueror was in charge of the human and material entities in that part of Africa. But suffice it to say that the African peoples even though enslaved, still owns the land. Trauma theory has been criticized for paying more attention on issues such as the wars that took place in Europe and their catastrophic consequences on people in that part of the world. Specifically, the horror of the Holocaust has been at the center of concern for trauma theorists such as Cathy Caruth and others. Stef Craps clearly highlighted this view when he posited that:

Remarkably, however, the founding text of the field (including Caruth's own work) largely fail to live up to this promise of cross-cultural ethical engagement. They fail on at least three counts: they marginalize or ignore traumatic experiences of non-western or minority cultures; they tend to take for granted the universal validity of definitions of trauma and recovery that have developed out of the history of western modernity; and they often favor or even prescribe a modernist aesthetic of fragmentation and aporia as uniquely suited to the task of bearing witness to trauma. (Craps 46)

When we look closely at Craps' position it becomes a critical matter for the field of trauma theory to come up with a more inclusive definition of the term. This becomes quite necessary when we consider the contemporary spread of radical Islamic ideological beliefs and the consequent insurgencies. These insurgencies - ranging from Al-Qaeda, IS, Taliban, Al-Shabab, and Boko Haram - all call for a radical re-examination of the term to include current traumatic 
experiences of minorities in various regions of the world. In line with this also, there is a need to delve into the colonial history of Africa and the Caribbean. This will require a careful examination of the traumatic experiences people suffered under Apartheid in South Africa and the brutalities of colonial administrations in the rest of the continent. The Indian subcontinent, South-East Asia and the Caribbean has had their fair share of physical and psychological trauma. Craps argued that failure to redefine the term would lead to: '...rather than promoting cross-cultural solidarity, trauma theory risks assisting in the perpetuation of the very beliefs, practices, and structures that maintain existing injustices and inequalities.' (Craps 46). It is therefore an urgent matter for theorists in the field to come up with a definition of the field which would take cognizance of critical issues that affect a vast majority of humanity that do not have access to the world's press. Craps again is of the opinion that: 'However, if trauma theory is to redeem its promise of cross-cultural ethical engagement, the sufferings of those belonging to non-Western or minority cultures must be given due recognition.' (Craps 46). This would tend to underline the need for trauma theory to specifically, highlight the physical and psychological traumatic experiences of weak and vulnerable people such as women and children who are targets of dehumanization of evil groups such as Boko Haram. Traumatic experiences suffered by these group especially, abductions and sexual slavery must be adequately captured within the purview of trauma theory. The whole idea is to draw attention to the theory to focus more adequately on literary texts from other parts of the world apart from Europe that highlights the traumatic experiences of vulnerable people.

\section{Theoretical Framework}

This essay will make use of Trauma theory to assess Andre Brink's novel Philida. Thephysical and psychological experiences of the main characters in the novel can be seen in the context of experiences that are traumatic for them. In this assessment we encounter a mix of history, memory, and narrative which all highlighted the effects of the institution of slavery in the South African Cape in 1832. Brink's style of rendering this experience is very important because he uses not only his family historical documents but he narrated events using the voices and perspectives of the slaves and their masters. The views of Cathy Caruth, Henry Krystal, and Stef Craps would be employed in the analysis.

\subsection{Definition of Trauma Theory}

According to Cathy Caruth trauma can be defined thus:

'In its most general definition, trauma describes an overwhelming experience of sudden or catastrophic events in which the response to the event occurs in the often delayed, uncontrolled repetitive appearance of hallucinations and other intrusive phenomena.' (Caruth 11).

In the novel Philida we are confronted with a situation in which the protagonist, Philida undergoes repeated, catastrophic and uncontrolled experiences in her position as a slave. She has no control whatsoever over circumstances as they affect her. She was a victim of physical and psychological abuse from her owner, Cornelis Brink and his son, Francois 'Frans' Brink. Frans sexually assaulted Philida repeatedly and this results in the birth of four children in which two died and two are living. Petronella 'Ouma Nella' also experienced catastrophic experience in her life which began from the time she was brought to the Cape in a slave ship. She endured horrifying experiences at the hands of her captors. She was later abused sexually by Pa Johannes. This experience led to the birth of Cornelis Brink who is now the master of the farm at Zandvliet. Although, she is now a free person yet, she is still oppressed by the past.

In relating the relationship between trauma and history Caruth has this to say:

The story of trauma, then, as the narrative of a belated experience, far from telling of an escape from reality- the escape from a death, or from its referential force-rather attests to its endless impact on life...The crisis at the core of many traumatic narratives...often emerges, indeed, as an urgent question: Is the trauma the encounter with death, or the ongoing experience of having survived it? At the core of these stories, I would suggest, is thus a double telling, the oscillation between a crisis of death and the correlative crisis of life: between the story of the unbearable nature of an event and the story of the unbearable nature of its survival. (Caruth 7).

Caruth is elucidating more on what trauma is in the context of catastrophic experience which is not an escape from the fact of having lived it; but the capacity of this experience to repeatedly intrude into the present with grave consequences. Trauma narratives such as the novel Philida is therefore, a rendition of a catastrophic event which in itself is quite hard to bear on the one hand; and the story of having survived the first event. For Caruth, both events-the real happening and the 'living' with what has happened is the core of trauma. This is so because the past tends to repeatedly intrude into the subconscious of the victim especially, through memory.

\section{2. 'Adult Catastrophic Psychic Trauma' (Krystal 80)}

In Philida there is another form of traumatic experience which some of the characters suffer from. This trauma has to do with aging. '...the adult catastrophic trauma state is determined by the presence of unavoidable danger...The adult traumatic state is initiated by the recognition of inevitable danger, and the surrendering to it.' (Krystal 80). This form of trauma is seen in the novel in the character of Cornelis Brink. The gradual and consistent decline in his wine business and farm led to physical and psychological issues for Cornelis Brink. Aging and trauma are also related to the ability of victims to experience pleasure: 'One need not belabor the many reasons why aging involves a gradual diminution in the potential for pleasure and gratification. If the process runs its full course, one is left to enjoy nothing but one's vegetative functions.' (Krystal 82). The decrease in sexual libido for Cornelis Brink becomes a recurring problem for him. Thus, this state of affair affects his basic psychology. 


\subsection{Trauma and Non-European Literary Texts}

This analysis will also look at the views of Stef Craps who feels that the current definition of trauma does not fully capture holistically, the experiences of people from non-European settings. He is concerned about the vast minority of victims whose traumatic experiences have not been captured in the mainstream discussions of trauma theory. He began by highlighting what trauma theory promised it will do.

Trauma theory is an area of cultural investigation that emerged in the early 1990s as a product of the so-called ethical turn affecting humanities. It promised to infuse the study of literary and cultural texts with new relevance. Amid accusations that literary scholarship, particularly in its deconstructive, poststructuralist, or textualist guise, had become indifferent or oblivious to 'what goes on in the real world'. (Craps 45).

Craps began by underlining the core reasons for the emergence of trauma theory. These are in the first instance, an ethical shift in focus and the injection of fresh relevance to literary texts. In a sense, trauma theory intends to engage with the questions of morality within the context of the mores and values of human interrelations. His contention is however, in the way the theory is currently carrying out this function. He maintained that trauma theory has failed to fulfil its 'promise of cross-cultural ethical engagement.' (Craps 46). He went on to say that the theory has set aside 'or ignore traumatic experiences of non-Western or minority cultures...' (Craps 46). The present definition of trauma has thus, taken Western history as a model for highlighting traumatic experiences of all peoples on the planet. Craps disagrees with this perspective which was espoused by leading theorist in the field such as Cathy Caruth: 'However, if trauma is to redeem its promise of cross-cultural ethical engagement, the sufferings of those belonging to non-Western or minority cultures must be given due recognition.' (Craps 46). Non-Western literary texts such as Philida require a unique place in trauma theory due solely to the nature of the type of trauma that its characters live with.

\section{Analysis}

In this section an attempt will be made to highlight key areas in the novel Philida where issues of trauma and traumatic experiences are clearly apparent. Traumatic experiences as has been pointed out earlier in this essay can be perceived not only in the lives of slaves like Philida or free slaves like Petronella; but this experience can be seen in slave masters such as Cornelis Brink and Pa Johannes. Thus, Andre Brink's narrative tends to give us a full picture of life in the South African Cape of the 1800s.

\subsection{Philida}

The action within this important novel revolves around the life of a young slave girl called Philida. The narrative began when the reader encounters her on her way to Stellenbosch to lodge a complaint to the Slave Protector, Mijnheer Lindenberg against her owner Cornelis Brink and his son Francois Gerhard Jacob Brink. Philida was sexually assaulted by Francois 'Frans' Brink for eight years. In the intervening period, they had four children. Two of these children are living while two had died. Frans had promised Philida that he will buy her freedom if she agrees to have sex with him. He later reneged on his earlier promise to her. Meanwhile, his parents are arranging a marriage of convenience for him with the daughter of Daniel Berrange - a wealthy slave owner. In essence, Philida is about to be dumped by Frans after he had promised not only to buy her freedom but to also set off a life with her. 'Eight years ago. Are you sure of that? How can you be so sure? Ja, it is eight years, I tell you, my Grootbaas.' (Philida 4). The first trauma for Philida was the fact of being a slave. The second traumatic experience was the sexual molestation she underwent with Frans. In each case she cannot fight against the situation. She was powerless to resist the physical and psychological brutality of being a slave and being turned into a sex object. The blunt and crude method of the Slave Protector's interrogation of Philida highlights the heartlessness of the person that is touted as a protector of slaves. He does not care about her feelings- after all, she is a slave:

I can feel myself going blunt inside, but I know I can't stop now, so I bite on my teeth and tell him: He do what a man do with a woman. And what would that be? I'm sure the Grootbaas will know about that. He says: I want to know exactly what he did. He takes me. How did he take you? ... I tell him: He naai me. (Philida 6).

In the exchange between Philida and the slave protector readers can clearly see the courage that she had exhibited. Philida was ready to confront the perceived injustice that was meted out to her by François Brink. After her session with the Slave Protector Philida was taken into custody to wait for Francois Brink to come and defend himself. She reminisced about her life in Zandvliet. The life of a slave was worth nothing. The law was also impotent as far as a slave is concerned: 'I mean, you can say the law give me the right to come and complain. But if you ask me, it's not the law that speak the last word in this land. It's everything that happen behind the law. That is what matter for the big men of the Caab.' (Philida 13). In essence, the law for the slave is like a toothless bull dog. A slave has no rights whatsoever. Philida's thoughts centers on both the physical and psychological trauma she had passed through as a slave:

My head remember this and that and lots of other stuff as well, but the thing that really remember is my body. Everything leaves its mark there. Some you can see, others you can't, but they all there. Burns and cuts and bruise. The scrape marks on my knees and my elbows and my heels, all kinds of marks. The beatings and the falls ... (Philida 14).

Memory and trauma are kin especially, in a situation such as the inhumanity of slavery. The marks of physical brutalities meted out to slaves are always a testament of who they are. These manifestations of evil tend to reawaken an earlier pain and thus, plague the victim. Philida continues to remember the soothing words of lust that Frans spoke to her when he wanted access to her body. He promised her freedom and shoes on her feet if she agrees to his overtures. These 
thoughts are indications of Philida's deep psychological trauma because the scene keeps recurring in her subconscious. Another deeply traumatic event for Philida was when Cornelis Brink brought in two slave boys to rape her under his supervision: 'Move your arse! He orders the first one. Baas? Get up on her, man! The youngster clambers on top of her. Now naai her! Baas?' (Philida 42). This inhuman act occurred in the presence of all inhabitants of Zandvliet farm. Cornelis Brink does not care how Philida feels - both the physical humiliation and the psychological trauma. To him she was not a person but a mere slave who is like any household item. This act of brutality and evil stayed within Philida's subconscious throughout the novel. Slaves had to endure the lies, denial, and betrayal of their masters especially when there are issues between them. Francois Brink denied having had any sexual relationship with Philida which led to their having four children: 'It doesn't mean anything, I replied. It's a slave's word, and mine is a white man's word.' (Philida 49). As far as Frans is concerned, his testimony will override that of Philida since he is white and she is black. This underscores the philosophy of slavery throughout the world. When he promised to buy her freedom, he did not seem to remember that Philida was not his slave but his father's. Now before the slave Protector, he asserted his neutrality. However, Philida's assertions were clearly proven when the slave Protector checked her child: 'With a deft movement of her body she shifted the child round to her front and opened her arms to make him sit up in her embrace, as the man moved closer to look straight into those two bright blue eyes. She said, here is the lie I told Grootbaas.' (Philida 50). But even with this incontrovertible prove the slave Protector refused to hold Frans liable. This goes further to underline the hypocrisy of the laws that purported to protect slaves. As Philida walks back to Zandvliet farm from Stellenbosch, the traumatic experience of what played out there continue recurring in her mind. The events forcefully reminded her once again that she does not belong in Zandvliet and the life of a slave is one that depends on someone telling you what to do and not what to do. Even the environment which Philida initially regarded as having an affinity with her, is now alien and in conspiracy with the slave masters. In part two of the novel, Cornelis Brink decided to sell off Philida at a slave auction because she seems to be in the way of the arranged marriage of convenience between his son Frans and the daughter of Daniel Berrange- Maria Berrange. The auction was another major traumatic experience for Philida. It entails leaving the people she has been close to such as Petronella, her Ouma Nella who has been like a mother to her. During the auction, Philida shuts up her mind to the inhumanity being enacted all around her: 'Philida keeps staring into the farthest distance and pretends to know nothing. She is no longer there.' (Philida 163). The act of shutting off her mind in itself is an indication of putting herself in a sort of suspended state, a resistance of the pain of what is happening.

\subsection{Petronella 'Ouma Nella'}

There are two critical traumatic experiences that Petronella had passed through that is, apart from the many years as a slave and later being free but, having nothing that she can call her own. The first trauma was how she was taken away from her home in Java and brought to the Cape:

That time on the ship, all the rows of us in the stomach of the ship, with chains on our arms and legs, so you could never stand up, and barely sit or lie down, all those rows of people in the dark, stinking and smelling from all sides, vomit and shit and piss and sweat, day and night, but it all feels like night, just now and then a small bowl of soup, more water than soup, that you throw up again, almost immediately. (Philida 118).

This was a harrowing experience whose gory and horrifying details will always remain lodged in the psyche of the victim such as Petronella. She went on to describe how the slave merchants never let up their inhuman treatment of the slaves in the ship hold. Another equally harrowing experience was how she was sexually abused by Pa Johannes, Cornelis Brinks' father. This event was told to the reader by Philida: 'My Ouma Nella tell me long ago what your father does to her...' (Philida 84). Petronella is the mother of Cornelis Brink and his siblings. However, being a slave, she never enjoyed the comfort of motherhood as the children are usually taken away from her. A situation like this would create a permanent and recurring wound in a victim's psyche.

\subsection{Cornelis Brink and Pa Johannes}

Cornelis Brink and Pa Johannes are son and father. In Philida both of them were also victims of traumatic experiences. Cornelis Brink was constantly plagued by the failure of his wine business and farm and also his loss of libido as a result of his age. These are recurring issues for him: 'Before I came to live at Zandvliet everything was going so well. Life seemed so ordered and predictable. I was a prosperous man.' (Philida 90). Poverty, ruin, and bankruptcy are starring Cornelis in the face and these are frightening prospects. When he attempted to rape Philida he could not consummate the brutal act due to his seeming impotence: 'I know what you wanted to do, Cornelis...If you didn't do anything, it can only be because you cannot do anything anymore and it won't be for lack of trying.' (Philida 89). Petronella describes Cornelis' situation very well, after all, she was his mother. He is no longer potent enough to have normal sexual relations. Pa Johannes was also a virtual prisoner of his extreme sexual urges. When his wife, Ma Magdalena couldn't assuage his urge and which has become a recurrent torment, 'Pa Johannes availed himself of the services of a handmaid to assuage his need. Very special among them was Petronella, who in her youth had been a delight to behold and a woman who'd known all the secrets of the heart and the flesh.' (Philida 93). The physical and psychological trauma faced by these characters tend to further underline the evil of slavery as an institution of man's evil against fellow man. In Philida there are other instances of traumatic experiences faced by slaves such as Labyn of Batavia whose wife was sexually abused and then, brutally murdered because she refused to cheat on him. He was castrated by the same people who murdered his wife. There was the murder and imprisonment of slaves who led a revolt against their masters. Galant the leader was killed and his head put on a pole. While, the other slaves were given lengthy prison terms with hard labor. 


\section{Conclusion}

Philida as a literary text used a microcosm in order to highlight a holistic historical dilemma and human evil against fellow human beings. Andre Brink delved into his family history and used it as a springboard for a wider discourse. The events within South Africa and the Cape specifically, gave the reader an authentic glimpse into events and happenings in the South African Cape of 1832. Brink brought his readers close to all the characters and most especially, the slaves. Most accounts of slavery try to put the reader into the psychical realms of the slave mind. However, Philida is in a class of its own. The novel has been able to critically assess the deep traumatic experiences of both the slaves and their masters. The insistent and recurring images of brutality and dehumanization - both physical and psychological - are the ingredients of slavery and which the key characters are victims. The intention of Brink was to clearly show the culpability of the slave institution in the cause for trauma not only to the slaves, but incidentally, to their masters too. The laws regarding slaves and slavery are nothing more than a whitewash covering deep seated hypocritical biases and lies. The slave has no voice, no right, and even in the presence of the so-called Slave Protector; the lying and prejudiced words of a white man are sacrosanct. This was made clear when Philida went to report Francois Brink, the son of her owner to the Slave Protector. The history of slaves and slavery in the world especially, in South Africa clearly shows a genetic mixture of the races. In Philida, the many cases of slave owners procreating with slave girls - Petronella and Pa Johannes, Philida and Francois Brink and so on - led to a mix of races which inevitably, broke down the artificial wall of a 'pure white' Afrikaner (Dutch) blood. In a sense, Andre Brink may be highlighting the futility of this absurd idea especially, in the minds of white Afrikaner minority community of which he was a member. The basic philosophy of slavery was also highlighted and its penchant for categorizing people into the white and black (slave) niches. Creating this type of niche tend to place whites as more intelligent than blacks. The novel Philida has proved that this demarcation is false and untenable. Again, the characters of Philida, Petronella, and Labyn of Batavia have proven that slaves and blacks for that matter, can be highly intelligent and witty.

\section{References}

i. Brink, A. (2013). Philida. London: Vintage.

ii. Caruth, C. (1996). Unclaimed Experience: Trauma, Narrative, and History. Baltimore, Maryland: The Johns Hopkins University Press. Pp 4-11.

iii. Craps, S. (2014) Beyond Eurocentrism: Trauma Theory in the Global Age. In Gert Buelens, Sam Durrant, and Robert Eaglestone, (Ed.) The Future of Trauma Theory: Contemporary Literary and Cultural Criticism. (Pp 4561) Abingdon, Oxon: Routledge.

iv. Krystal, H. (1995) Trauma and Aging: A Thirty-Year Follow-Up. In Caruth, Cathy (Ed) Trauma: Explorations in Memory. (Pp 76-99). Baltimore, Maryland: The Johns Hopkins University Press.

v. Whitehead, A. (2004) Trauma Fiction. Edinburgh: Edinburgh University Press. P. 81 